\section{CONJUNCTIVAL BIOPSY IN SARCOIDOSIS}

BY

RONALD CRICK, F.R.C.S.

CLIFFORD HOYLE, M.D., F.R.C.P.

AND

GORDON MATHER, M.D., M.R.C.P.

From King's College Haspital, London

This is a preliminary report of a rapid and easy method of confirming the diagnosis in patients with suspected sarcoidosis. Isolated cases of conjunctival sarcoidosis have been described from time to time, but the condition has generally been believed to be quite rare (Woods, 1951). On the contrary, we have so often found it in patients with generalized sarcoidosis that conjunctival biopsy would appear to have diagnostic value even when

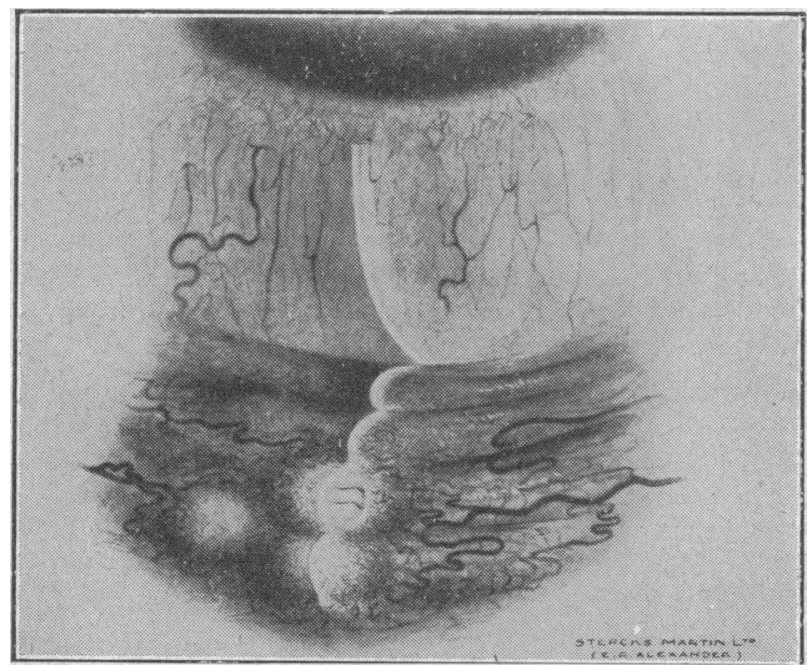

FIG. 1.-Follicles in the lower conjunctival fornix illuminated by the slit-lamp beam, the lower lid being everted. (Approximately $\times 12$.)

there are no ocular symptoms. The method was developed after seeing a patient who presented with follicles in the fornix and bulbar conjunctiva and who was found to have generalized sarcoidosis (Crick and Mather, 1954). A conjunctival biopsy revealed epithelioid cell structures typical of sarcoidosis, which were also found in the liver and lymph nodes. These sarcoid lesions show no caseation, are composed predominantly of reticulo-endothelial ("epithelioid") cells with occasional multinucleate giant cells, and are surrounded by a narrow zone of lymphocytes and fibroblasts. Subsequently, isolated follicles were seen during routine slit-lamp examinations of patients with sarcoidosis (Fig. 1). Biopsy of these demonstrated sarcoid lesions similar to those already seen in other tissues. The method was then used in an attempt to separate uveitis caused by sarcoidosis from other forms. Finally, conjunctival biopsies were used as a means of histological confirmation of sarcoidosis in patients thought to have the disease, even though there was no obvious ocular involvement, but in whom biopsies elsewhere were either not possible or else had proved negative.

The follicles are just visible to the naked eye, but are best seen with the slit-lamp: sometimes they are con- fluent. They are small elevations which are translucent and slightly yellow in colour. Follicies are usually found in the fornices, but may be encountered in the bulbar conjunctiva, sometimes as part of a sclerokeratitis (Fig. 2). Examples of such lesions in the buibar conjunctiva have recently been reported (Ashton, 1954 ; Klein et al., 1955; Crick, 1955). When examined microscopically the follicles may be seen to contain sarcoid lesions resembling those in other organs, but

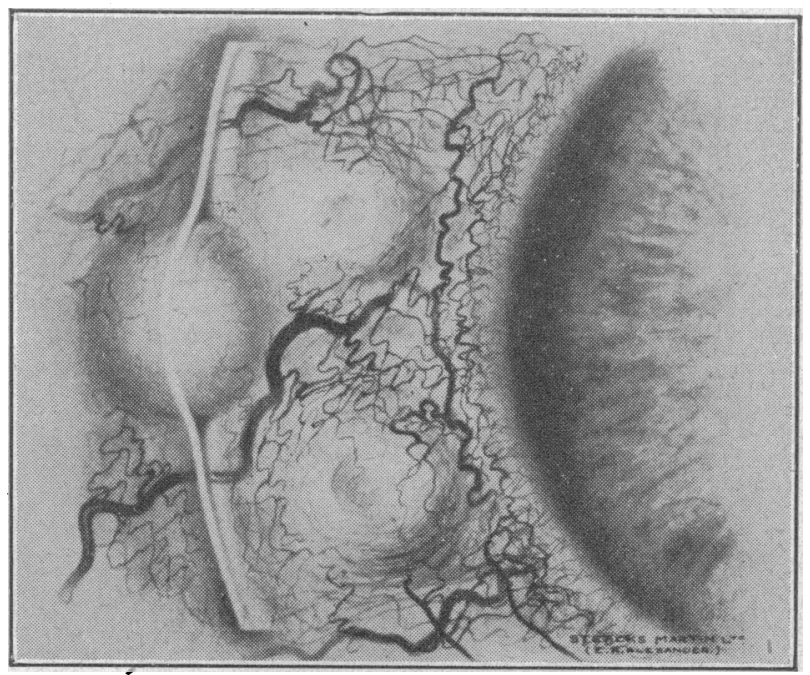

FIG. 2.-Follicles in the bulbar conjunctiva illuminated by the slit-lamp beam. (Approximately $\times 12$.)

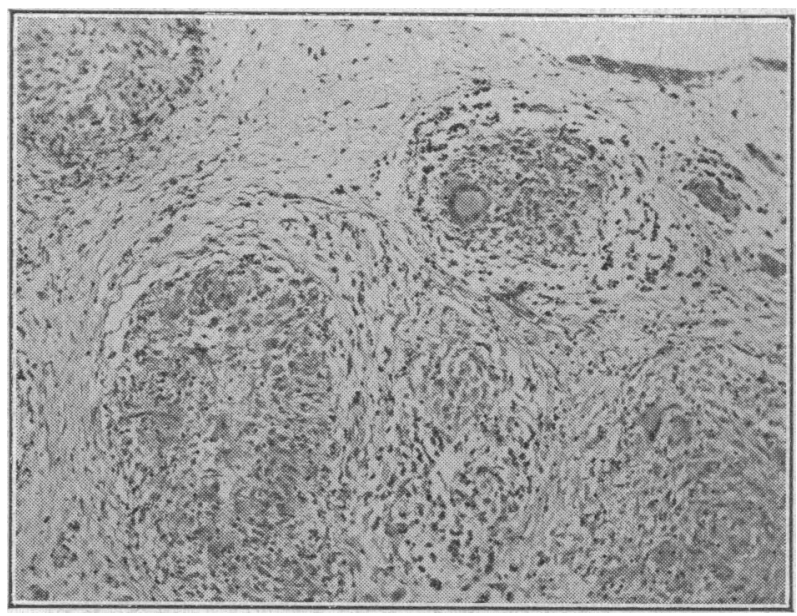

FIG. 3.-Conjunctival biopsy showing several epithelioid cell granulomas. (H. and E. stain. $\times 75$.)

are often surrounded by the lymphocytes that are so common in the subconjunctival connective tissue (Fig. 3). Biopsy material occasionally contains lymphoid tissue with germinal centres which should not be confused with sarcoid lesions.

\section{Methods and Results}

Three drops of $4 \%$ cocaine solution are instilled into the conjunctival sac at two-minute intervals. A small fold of fornix conjunctiva about $2 \mathrm{~mm}$. long containing follicles is grasped with forceps and snipped off with one cut of the scissors. There is usually no pain, but occasionally a momentary prick is felt. A suture is unnecessary and there is little haemorrhage - at the most slight capillary oozing. Chloramphenicol ointment $1 \%$ is applied but no dressing is required. The site of the biopsy heals completely in a few days and neither infection nor symblepharon has occurred. 
The specimen is fixed in formol-saline and 50 serial sections are cut and examined from each.

The procedure for biopsy of the bulbar conjunctiva is similar except that a conjunctival suture is required to prevent retraction of the edges of the incision and the eye is kept covered for two or three days.

Twenty-eight conjunctival biopsies have been done. Ten were on material from patients with generalized sarcoidosis without ocular symptoms. Sarcoid lesions were found in three: one of these had histological confirmation by a liver biopsy and another showed typical sarcoid lesions in the conjunctiva even though a previous liver biopsy had not done so. Eighteen were patients who presented with uveitis or episcleritis of a type which suggested the possibility of sarcoidosis. Six of these were found to have generalized sarcoidosis, and four of the six had a positive conjunctival biopsy. The remaining 12 had no signs of systemic sarcoidosis, but in three of these typical sarcoid lesions were found at the biopsy. Thus in 16 patients with the generalized disease a positive conjunctival biopsy was obtained in seven.

\section{Comment}

Interpretation of the histology is more difficult than in liver or lymph nodes owing to the normal presence beneath the conjunctival mucous membrane of chronic inflammatory cells and lymphoid tissue. It is for this reason that serial sections are essential, also familiarity with the histology of sarcoidosis elsewhere. Sometimes a suspicious collection of cells proves to be the edge of a sarcoid lesion when it is traced through serial sections; on other occasions the appearance remains non-specific.

Conjunctival biopsy is a simple procedure which can be done in the out-patient department, and hence has an advantage over liver and lymph-node biopsy.

Our results also show that typical sarcoid lesions occur in a significant proportion of patients. For these reasons conjunctival biopsy warrants further trial as a means of obtaining histological evidence of sarcoidosis.

\section{Summary}

Conjunctival lesions in sarcoidosis are more common than has hitherto been suspected. A simple method of conjunctival biopsy is described which has been used in 28 cases suspected of having the disease. Results so far suggest that the procedure will prove to be of diagnostic value in sarcoidosis.

We wish to thank Professor H. A. Magnus and the medical and technical staff of his department for the histological preparations and their interpretation, and Mr. E. R. Alexander and Mr. W. Smith for the illustrations.

\section{REFERENCES}

Ashton, N., Acta XVII int. Congr. Ophthal. (Montreal-New York. 1954), In press.

Crick, R. P. (1955). Trans. ophthal. Soc. U.K. In press.

- and Mather, H. G. (1954). Brit. J. Tuberc., 48, 204.

Klein, M., Calvert, R. J., Joseph, W. E., and Smith, E. (1955), Brit. J. Ophthal., 39, 416.

Woods, A. C. (1951). "Sarcoidosis" in Systemic Ophthalmology, edited by A. Sorsby, p. 195 . Butterworth, London.

The London County Council's "Safety in the Home" week, starting on November 14 , is intended to arouse public awareness to the dangers of accidents in the home, and to suggest ways and means of reducing the alarming number of deaths and injuries. Special emphasis will be laid on the avoidance by simple precautions of hazards which result in burns and scalds. There will be a "Burns and Scalds" exhibition during the week, in the Belvedere Road entrance to the County Hall. As well as the widespread use of posters and leaflets, a short film called "Dangerous Ages" will be shown at a number of London cinemas.

\section{SOME PROBLEMS IN THE MANAGEMENT OF THE AGED* \\ BY}

\author{
I. D. GRANT, M.B., Ch.B. \\ In General Prictice, Glasgow
}

When it was suggested that I should contribute a paper at the Joint Meeting, the choice of a subject gave me much thought, for I have no academic background, and have, for 35 years, been engaged only in general practice, a sphere in which the art of medicine is perhaps as important as the science. In recent years the study of geriatrics has assumed an ever-increasing importance in our everyday life and has brought home to all of us the inevitability of old age; so it may be of interest to those living in a more free political economy to hear of some of the difficulties which old age presents in the Welfare State. Socialized or nationalized medicine is now a feature of political propaganda in almost every educated country, and in the foreseeable future you, in Canada, are almost bound to be faced with some form of national health and welfare services, and, if so, you may benefit greatly from our mistakes. I do not pretend to tell you anything you do not already know. I shall only try to indicate some of the difficulties we in Britain are endeavouring to solve.

"Grow old along with me. The best is vet to be. The last of life for which the first was made." So wrote Robert Browning. But if we are to travel to these Elysian Fields we must make adequate preparations for the journey. As a family doctor, I have been consulted on many occasions by those approaching retirement on how they can attain that "unhoped serene that men call age" with a peaceful, happy, and contented mind. I tell them: (1) have at least one ambitious project you would like to attain; (2) consider your income and draw up a tentative budget of expenditure - financial worries are a very big source of misery and unhappiness, leading to mental and physical ill-health; (3) envisage how you will spend your enforced leisure and draw up a tentative programme for your activities, but please make it flexible and elastic-the most unhappy old people I know are those who strive to live by rule and rote; (4) make a point of helping others and undertake some form of social work to avoid the awful evil of self-absorption, remembering that "age is opportunity no less than youth itself though in another dress, and as the evening twilight fades away the sky is filled with stars invisible by day." What, then, do we mean by old age? There is still much truth in the Biblical definition, "The days of our years are threescore years and ten; and if by reason of strength they be fourscore years, yet is their strength labour and sorrow."

\section{A Mounting Problem}

In Britain, administratively, we regard women at 60 and men at 65 as having reached an age justifying retirement and qualifying to draw an old age pension. Our most recent census, in 1951 , showed that $12 \%$ of the population came into this category, but, of these, over $1,000,000$ remained at work. The expectation of life has increased considerably in the past two decades and far exceeds the old Hindu adage which divided the span of life into "Twenty years to learn, twenty years to work, and twenty years to pray." In 1941 there were in Britain four and a half million people over

* Read in the Section of General Practice at the Joint Annual Meeting of the British Medical Association, Canadian Medical Association, and Ontario Medical-Association, Toronto, 1955. 